\title{
Thermal Characterization and Lifetime Estimation of the Humus Lombricospt
}

\author{
Tulio Andres Florez, Gladis Miriam Aparicio \\ Ginsai Group, Universidad Autónoma de Occidente, Cali, Colombia \\ Email: taflorez@gmail.com, gmaparicio@uao.edu.co
}

Received November 25, 2013; revised December 26, 2013; accepted January 6, 2014

Copyright (c) 2014 Tulio Andres Florez, Gladis Miriam Aparicio. This is an open access article distributed under the Creative Commons Attribution License, which permits unrestricted use, distribution, and reproduction in any medium, provided the original work is properly cited. In accordance of the Creative Commons Attribution License all Copyrights (C) 2014 are reserved for SCIRP and the owner of the intellectual property Tulio Andres Florez, Gladis Miriam Aparicio. All Copyright (c 2014 are guarded by law and by SCIRP as a guardian.

\section{ABSTRACT}

Through this study, the humus produced in the breeding place of Universidad Autonoma de Occidente was thermally characterized. The humus was submitted to a heating program controlled by the Differential Scanning Calorimetry (DSC) technique to characterize the type of transition, Thermogravimetry (TGA) to study the equilibrium of phasesand Mass Spectrometry (MS) coupled to TGA to identify detached elements in a temperature range. The temperature range used in this study was $30^{\circ} \mathrm{C}<\mathrm{T}<600^{\circ} \mathrm{C}$. The energy required for the water desorption in the humus has been found in this study. The humus showed a quick desorption between $30^{\circ} \mathrm{C} \leq$ $\mathrm{T}_{\text {Desorption }} \leq 110^{\circ} \mathrm{C}$ at a heating rate of $10^{\circ} \mathrm{C} / \mathrm{min}$ and presented decomposition around $250^{\circ} \mathrm{C}$. Moreover, the kinetics of the desorption of the humus was studied to obtain the activation energy three TGA measures for three different heating rates. The average activation energy was about $26 \mathrm{~kJ} / \mathrm{Mol}$. This result was carried out to obtain an estimation of the desorption time of water in the range from room temperature to the decomposition temperature around $350^{\circ} \mathrm{C}$.

\section{KEYWORDS}

Thermal Analysis; Thermogravimetry (TGA); Differential Scanning Calorimetry (DSC); Mass Spectrometry (MS); Activation Energy; Decomposition Kinetics; Humus

\section{Introduction}

The red Californian worm compost is made from the skin of Solanum tuberosum (potato), cattle excrements (cow dung), plant sludge from waste water treatment WWTP at Universidad Autónoma de Occidente (UAO) and leaves that are cut to maintain symmetry in the garden. These four components are supplied to the Californian worms.

The Differential Scanning Calorimetry (DSC) technique quantifies some physical properties of the materials such as the heat capacity, the melting temperature, the crystallization, the glass transition temperature, the enthalpy of the reactions, among others [1].

The Thermogravimetry (TGA) technique quantifies the weight losses which are associated with the dehydration or decomposition of the material or compound being analyzed. This technique is supplemented with the Mass Spectrometry which identifies the gases that are released as they are subjected to different temperatures. In this way it is possible to obtain a qualitative analysis of the analyzed material or compound. This work seeks to establish alterations in the physical properties of the humus due to variations in temperature through the study of the heating capacity, the activation energy and the estimated lifetime. Moreover, it seeks to analyze phenomena such as dehydration and evaporation of the components of humus.

\section{Materials and Methods}

The red californian worm compost elaborated at UAO is located in an enclosure of $6.30 \times 2.30 \mathrm{~m}$ and a height of $0.55 \mathrm{~m}$. For the elaboration of humus the compounds listed in Table 1 are supplied to the worms [2].

For the thermal analysis the humus was taken directly from the breeding place to be thermally characterized at the Thermal Analysis Laboratory (TAL). The characte- 
Table 1. Compounds supplied to the californian worms for the production of humus.

\begin{tabular}{lccc}
\hline & Compound & Days & Quantity \\
\hline 1 & Cow dung & 15 & $60 \mathrm{~kg}$ \\
2 & Plant sludg & 15 & $45 \mathrm{~kg}$ \\
3 & Gardening & 15 & $120 \mathrm{~kg}$ \\
4 & Skin & 15 & $40 \mathrm{~kg}$ \\
\hline
\end{tabular}

rization was done through a Differential Scanning Calorimetry DSC Q2000 with a temperature range of $30^{\circ} \mathrm{C}<$ $\mathrm{T}<600^{\circ} \mathrm{C}$ at a heating rate of $10^{\circ} \mathrm{C} / \mathrm{min}$ and a Thermogravimetry TGA Q500 with a temperature range of $30^{\circ} \mathrm{C}$ $<\mathrm{T}<600^{\circ} \mathrm{C}$ at a heating rate of $10^{\circ} \mathrm{C} / \mathrm{min}$. The TGA evaporated elements were passed directly to a mass spectrometry MS Discovery (TA Instruments brand), where the detached elements were analyzed.

The collected humus sample was exposed to the method shown in Table 2 according to the characterizationtechnique.

\section{Results and Discussion}

\subsection{Differential Scanning Calorimetry (DSC) and Thermogravimetry (TGA)}

Figure 1 shows the DSC and TGA Thermograms for the humus sample in a nitrogen atmosphere conducted at a heating rate of $10^{\circ} \mathrm{C} / \mathrm{min}$. The TGA curve shows two degradations: the first from room temperature to $100^{\circ} \mathrm{C}$ atributed to water desorption or moisture loss, shows a weight loss of about $52.8 \%$; the second degradation is observed at temperatures between $200^{\circ} \mathrm{C}$ and $400^{\circ} \mathrm{C}$, attributed to proceses of decomposition of organic material showing a weight loss in the humus of about $10.7 \%$.

The DSC thermogram displays an endothermic anomaly around $90^{\circ} \mathrm{C}$ which corresponds to the desorption process with an associated enthalpy of $1200 \mathrm{~J} / \mathrm{g}$. The second anomaly is shown in the box in Figure 1. It corresponds to an endothermic process around $400^{\circ} \mathrm{C}$ and is attributed to the process of decomposition.

Table 3 summarizes the thermal stability of the humus in the two temperature ranges mentioned.

Table 4 summarizes the phase behavior of the humus within the two temperature ranges mentioned, indicating the enthalpies of the process.

\subsection{Mass Spectrometry (MS)}

Figure 2 shows the TGA thermogram simultaneously with the registered masses by MS.

The masses are generated by the release of gases that occurs during the thermal scanning process to which the humus sample was programmed under an inert atmosphere of nitrogen. The released masses whose $\mathrm{m} / \mathrm{e}$ ratio belongs to the values $16,18,28,32$ and 44 , are asso-
Table 2. Description of the Heating Program.

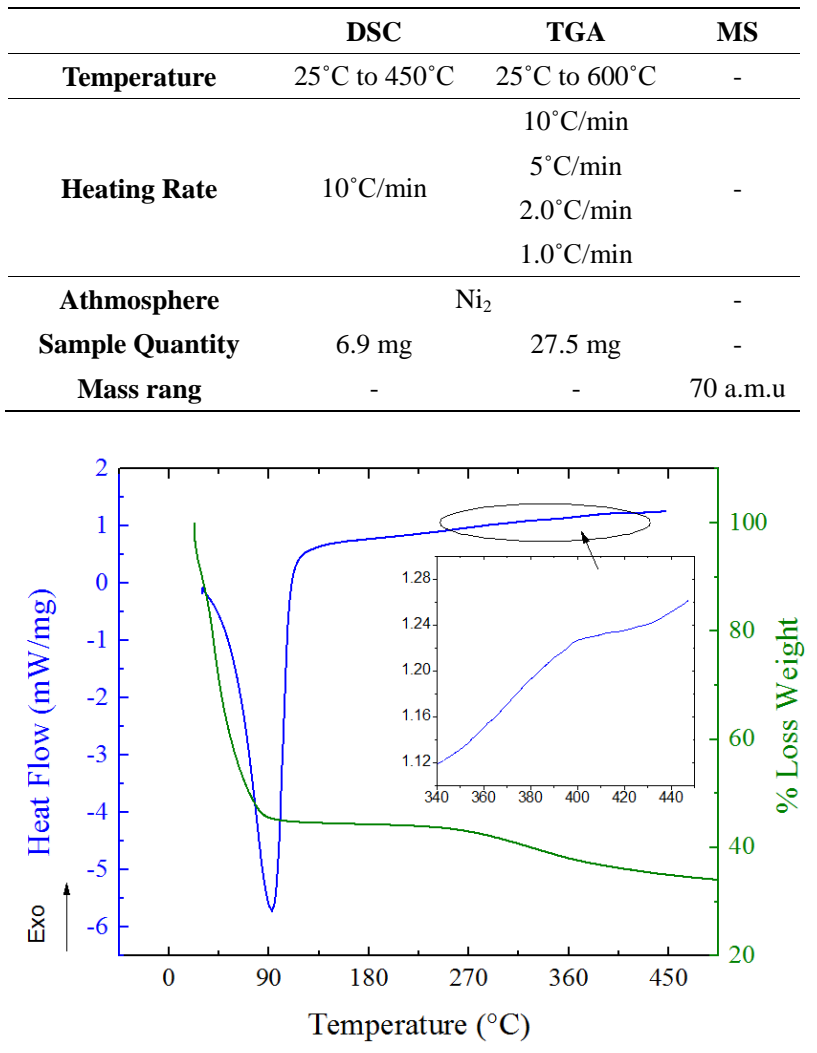

Figure 1. DSC and TGA Thermograms.

Table 3. Degradations present in the humus.

\begin{tabular}{cccc}
\hline \multicolumn{4}{c}{ TGA } \\
\hline $\begin{array}{c}\text { Temperature } \\
\text { Range }\left({ }^{\circ} \mathrm{C}\right)\end{array}$ & $\begin{array}{c}\text { Initial Weight } \\
(\mathrm{mg})\end{array}$ & Weight loss (mg) \% Weight loss \\
\hline $25-150$ & 49.118 & 26.76 & 54.49 \\
$200-600$ & 27.009 & 2.889 & 67.07 \\
\hline
\end{tabular}

Table 4. Anomalies present in the humus.

\begin{tabular}{ccc}
\hline \multicolumn{3}{c}{ DSC } \\
\hline Anomaly $\left({ }^{\circ} \mathrm{C}\right)$ & Onset Point $\left({ }^{\circ} \mathrm{C}\right)$ & Enthalpy $(\mathrm{J} / \mathrm{g})$ \\
\hline $25-150$ & 56.16 & 1271 \\
$200-600$ & 360.28 & 6.09 \\
\hline
\end{tabular}

ciated with: $\mathrm{O}, \mathrm{H}_{2} \mathrm{O}, \mathrm{CO}, \mathrm{O}_{2}$ and $\mathrm{CO}_{2}$.

The data shows that the first anomaly occurs around $100^{\circ} \mathrm{C}$ due to the release of $\mathrm{H}_{2} \mathrm{O}$. The second anomaly starts around $200^{\circ} \mathrm{C}$ and ends around $400^{\circ} \mathrm{C}$ due to the release of $\mathrm{CO}_{2}$. The results also show that the levels of $\mathrm{O}$, $\mathrm{H}_{2} \mathrm{O}$, CO and $\mathrm{O}_{2}$ decrease while the level of $\mathrm{CO}_{2}$ increases. This shows the decomposition that undergoes the humus.

According to the TGA thermogram the humus decomposes in two phases, in the first due to dehydration and in the second due to the release of $\mathrm{CO}_{2}$. 


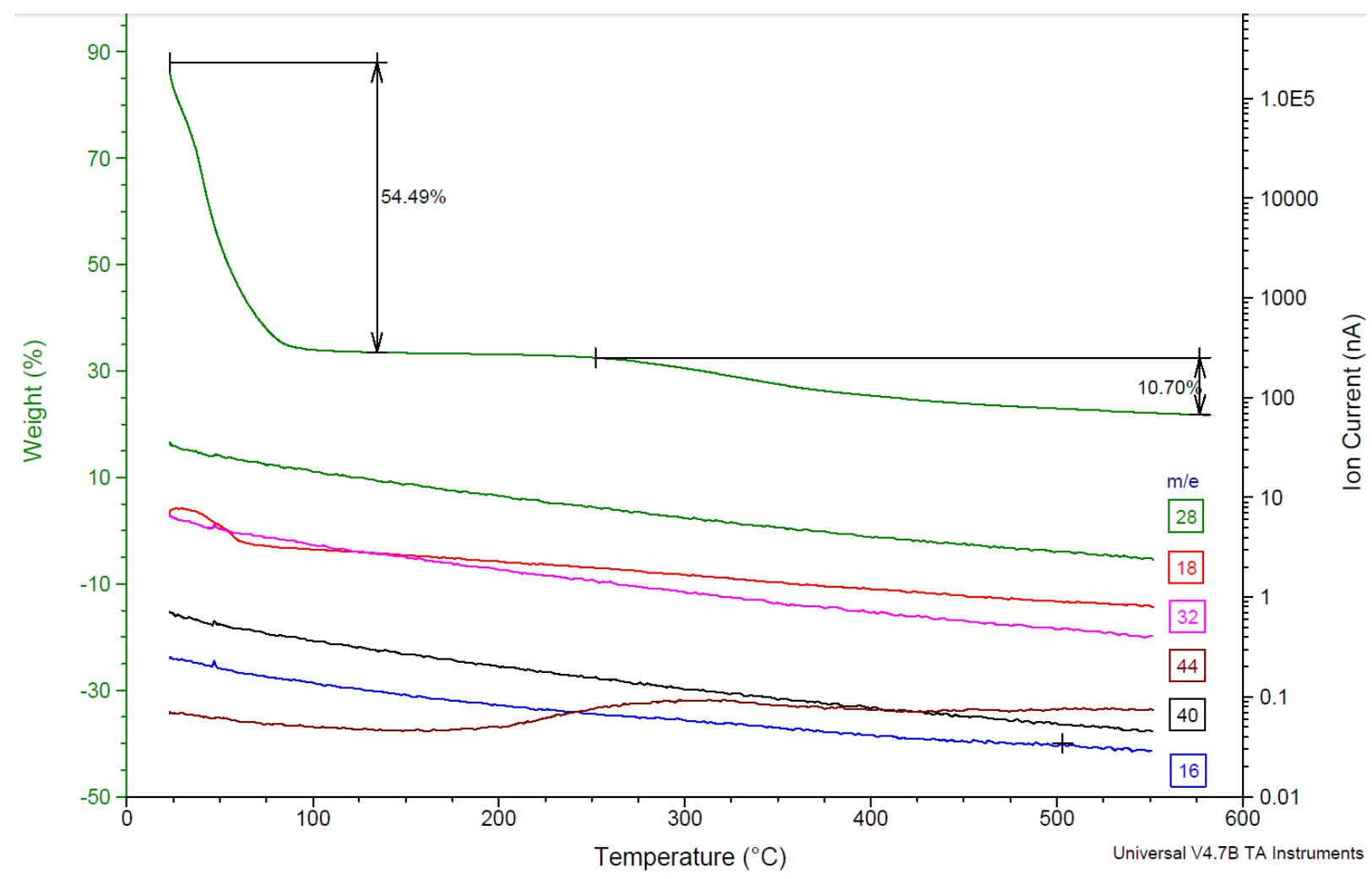

Figure 2. TGA and MS Thermograms.

\subsection{Kinetic Study of the Humus Based on Thermogravimetic Results}

The thermogram in Figure 3 shows the weight loss of the humus exposed to different heating rates: $2^{\circ} \mathrm{C}, 5^{\circ} \mathrm{C}$ and $10^{\circ} \mathrm{C} / \mathrm{min}$.

Figure 3 gives information on the desorption kinetics based on the Flynn and Wall method [3] used in this study which describes a quick and direct way to determine the activation energy of a material from thermogravimetric data and based on the ASTM E1641 norm [4] which suggest the following procedure:

- Subject the material to at least three different heating rates $\left(1^{\circ} \mathrm{C} / \mathrm{min}-10^{\circ} \mathrm{C} / \mathrm{min}\right)$.

- Determine the temperature at which there is loss of mass of the material (typically 10\%).

- Graph the heating rate vs. 1/T.

- Perform the linearization of the graph: heating rate versus $1 / \mathrm{T}$.

- Calculate the activation energy (iterative procedure) and the pre-exponential factor of Arrhenius starting from the slope found in the linearization.

Plotting the heating rates versus the inverse of the temperature in degrees kelvin $(1 / \mathrm{k})$, as illustrated in Figure 4, we obtained three linearizations which correspond to the three measures of the humus. These establish that the derivative expression (dlog (B)/dlog (1/t)) is the slope of the linearization obtained in Figure 4.

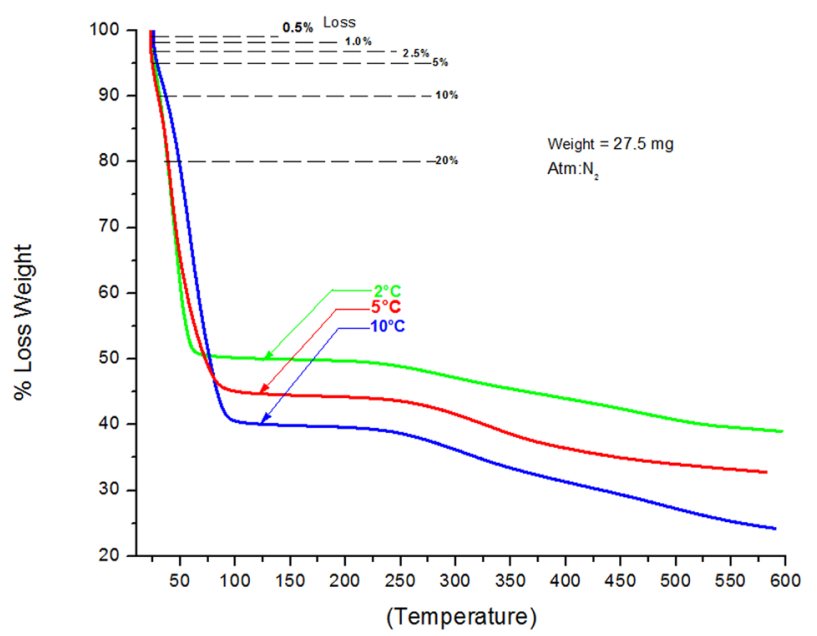

Figure 3. TGA Thermograms at Different Heating Rates.

$$
E_{a}=-\frac{R}{b}+\left[\frac{E \log \beta}{\mathrm{d}(1 / T)}\right]
$$

Where:

$E_{a}$ : Activation Energy

$R$ : Constant $(8.314 \mathrm{~J} / \mathrm{mol})$

$T$ : Temperature $(\mathrm{k})$

$\beta$ : Heating Rate $\left({ }^{\circ} \mathrm{C} / \mathrm{min}\right)$

$b$ : Constant (0.457).

Table 5 shows values for the activation energy and the 


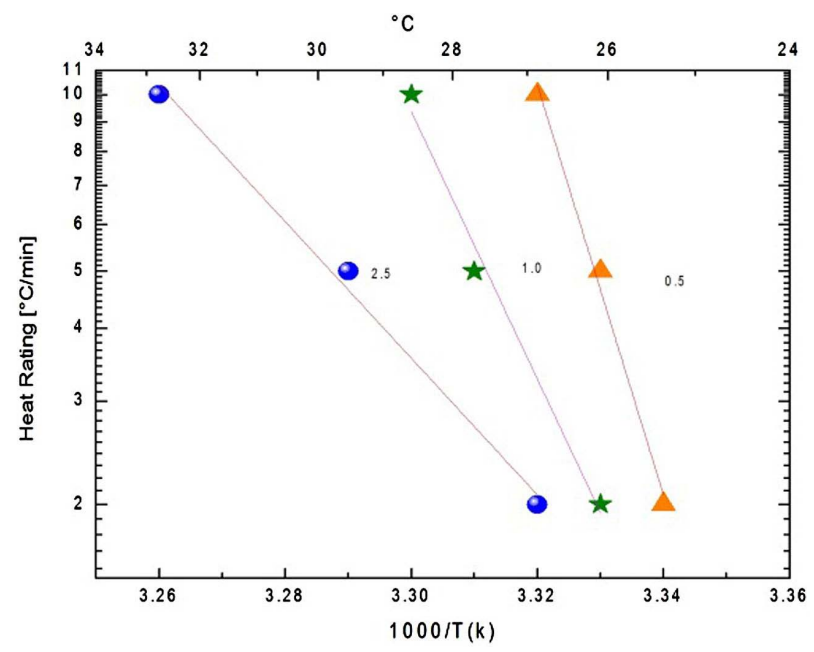

Figure 4. Relationship between the heating rate and the inverse of the temperature.

Table 5. Activation energy for different weight losses humus.

\begin{tabular}{ccc}
\hline Conversion \% & $\frac{E}{R T}$ & Ea [KJ/Mol] \\
\hline $\mathbf{0 . 5}$ & 11.649 & 33 \\
$\mathbf{1 . 0}$ & 22.813 & 65 \\
$\mathbf{2 . 5}$ & 34.948 & 96 \\
\hline
\end{tabular}

corresponding values for $\mathrm{E} / \mathrm{RT}$ ) calculated for the three conversion cases shown in Figure 4. All the activation energy values calculated on the first iteration yield $E /(R T)$ values within the expected range. Thus, no additional iterations are required.

In his work Toop [5] demonstrates in detail how to obtain a value $b$ within the range $10 \leq E /(R T) \leq 40$.

Once obtained the activation energy for the different conversions used, the useful lifetime of the humus can be estimated with theToop method [5]:

$$
T_{F}=\frac{E / R}{\ln t_{f}-\ln \left[\frac{E}{\beta R} \cdot P\left(X_{F}\right)\right]} ;
$$

where:

$t_{f}$ : Estimated Time to Failure (min)

$E$ : Activation Energy $(\mathrm{J} / \mathrm{mol})$

$T_{f:}$ Failure Temperature (K)

$R$ : Gas Constant $(8.134 \mathrm{~J} / \mathrm{mol} \cdot \mathrm{K})$

$P\left(X_{F}\right)$ : A function whose values depend on $E$ at the failure temperature.

Tc: Temperature for $5 \%$ Loss at $b(\mathrm{~K})$

$\beta$ : Heating Rate $\left({ }^{\circ} \mathrm{C} / \mathrm{min}\right)$

$$
-\log P\left(x^{\prime}\right)=-\log \left[\frac{1}{x^{\prime} e^{x^{\prime}}}-\int_{x^{\prime}}^{\infty} \frac{\mathrm{d} x}{x e^{x}}\right]
$$

Figure 5 shows the estimated dehydration time of the humus at a particular temperature. This means that if the

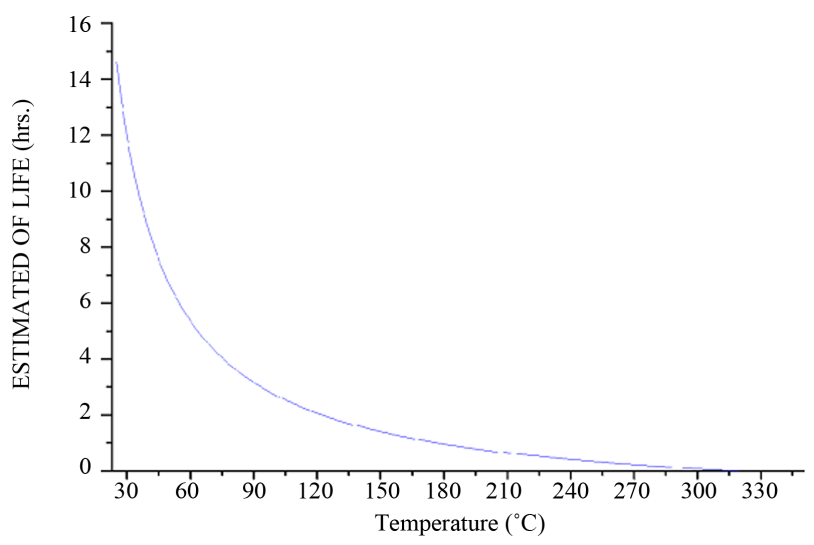

Figure 5. Desorption time of the Humus in an atmosphere of $\mathbf{N}_{2}$.

humus would be in a moisture-free atmosphere without any type of irrigation, it would maintain its hydration properties at a temperature of $30^{\circ} \mathrm{C}$ for at least14 hours. Thus, if the humus would be exposed to a temperature of $60^{\circ} \mathrm{C}$ its properties would be maintained only for 5 hours.

\section{Conclusions}

For the first time we study the behavior of dehydration and decomposition of humus by californian earthworms produced through thermal analysis techniques such as thermogravimetric, Differential Scanning Calorimetry and Mass Spectrometry.

The results show a strong connection between the results of the DSC and the TGA techniques. This confirms that humus presents two phases, the first attributed to the dehydration of the humus and the second attributed to its decomposition hereby releasing $\mathrm{CO}_{2}$. This was expected based on the composition of the humus.

Using the Flynn and Wall method based on thermogravimetric data, we identified the useful lifetime of the humus. This has been done by focusing on the desorption zone to estimate the time in which the properties are conserved depending on the exposure temperature. This estimated value of the desorption time of water shows that the desorption process can take around 14 hours at a temperature between $25^{\circ} \mathrm{C}$ and $30^{\circ} \mathrm{C}$.

\section{Acknowledgements}

The authors express their sincere gratitude to University Autonoma de Occidente who made the development and publication of this study posible through access to the Thermal Analysis laboratory.

\section{REFERENCES}

[1] G. W. H. Höhne, W. F. Hemminger and H.-J. Flammersheim, "Differential Scanning Calorimetry," 2nd Edition, Springer, Heidelberg, 2010, pp. 71-91. 
[2] F. J. Stevenson, "Humus Chemistry: Genesis, Composition, Reactions,” 2nd Edition, Wiley, 1994, pp. 188-208.

[3] J. H. Flynn and L. A. Wall, “A Quick, Direct Method for the Determination of Activation Energy from Thermogravimetric Data,” Polymer Letters Vol. 4, No. 5, 1966, pp. 323-328.

http://dx.doi.org/10.1002/pol.1966.110040504

[4] ASTM Test Method E1641, "Standard Test Method for
Decomposition Kinetics by Thermogravimetry," ASTM Book of Standards 14.02, American Society for Testing and Materials, 1994, pp. 1042-1046.

[5] D. J. Toop, "Theory of Life Testing and Use of Thermogravimetric Analysis to Predict the Thermal Life of Wire Enamels," IEEE Transactions on Electrical Insulation, Vol. EI-6, No. 1, 1971, pp. 2-14. 